RESEARCH NOTE

\title{
Aspergillus rot of ripe mangoes ( Mangifera indica L.) var. Ambalavi, Willard and Karuthakolumban
}

\author{
N. Krishnapillai ${ }^{{ }^{*}}$ and R.S. Wilson Wijeratnam ${ }^{2}$ \\ ${ }^{1}$ Department of Botany, Faculty of Science, University of Jaffna, Jaffna. \\ ${ }^{2}$ Industrial Technology Institute, 363, Bauddhaloka Mawatha, Colombo 7.
}

Revised: 16 November 2012 ; Accepted: 19 November 2012

Keywords: Aspergillus niger, Aspergillus rot, mangoes.

Karuthakolumban, Willard and Ambalavi are considered the desirable dessert mango varieties in Jaffna. These varieties are, in general, grown in home gardens. Postharvest losses of mangoes are high in Jaffna due to two major postharvest diseases, stem-end rot and anthracnose.

However, in July 2009 approximately $10 \%$ of the harvested mangoes var. Ambalavi from a home garden at Thirunelvely were observed with different symptoms (Figure 1). The symptoms were first observed as small, light yellow colour suppressed lesions around the stemend region. The lesions increased in size resulting in depressed mesocarp and a soft rot condition. The centre of the lesion became sunken and was covered with brownish black spores.

Isolated colonies of the causal organism on potato dextrose agar (PDA) were initially white in colour. Black colour conidia production was observed 36 hours after inoculation and was followed by the appearance of black colour colonies with a diameter of $8 \mathrm{~cm}$, three days after inoculation. The reverse side of culture plates was off-white in colour with a fracture like appearance. The hyaline, septate mycelia with black colour conidia and the spore bearing structures are characteristics of Aspergillus niger (Bennett, 2010). ' $\mathrm{T}$ ' shaped foot cells that produce a single conidiophore were observed. The size and arrangement of the conidial heads as well as the colour of the spores are important morphological taxonomic characteristics used in the identification of Aspergillus.
Koch's postulates were satisfied by transferring mycelial discs of $5 \mathrm{~mm}$ diameter from a five day-old culture grown on PDA to the surface sterilized, wounded, mature Ambalavi mangoes. Non inoculated Ambalavi mangoes were kept as control. The control and the inoculated mangoes were kept at ambient temperature (30$34{ }^{\circ} \mathrm{C}$ ). Typical symptoms were developed in the inoculated mangoes within five to six days (Figure 1) while there was no rotting observed in the control fruits. Koch's postulates were confirmed by re-isolating the pathogen from inoculated fruits.

The diseased mangoes were brought to the Post harvest Laboratory, Industrial Technology Institute, Colombo 7 and the causative organism was confirmed as $A$. niger (Figure 2) on the basis of cultural and morphological characteristics (Watanabe, 2002). A. niger is an ubiquitous filamentous fungus found in soil, air, decaying plant material and in a large number of foods and feeds all over the world (Perrone et al., 2007; Pitt \& Hocking, 2009; Gautam et al., 2011).

During April to August 2011, Aspergillus rot was recorded in the most popular dessert mango varieties in Jaffna, Karuthakolumban and Willard. It was thus concluded that Aspergillus rot is also an important postharvest problem in Jaffna with three years subsequent observations in markets and home gardens during 2009 to 2011. Based on morphological characters and pathogenicity test the causative organism was confirmed as A. niger.

Aspergillus rot caused by A. niger have been reported in other countries of the world (Prakash \& Raoof, 1989;

\footnotetext{
"Corresponding author (nahmagal@gmail.com)
} 
Johnson et al., 1997). However, Aspergillus rot in mangoes has not been previously reported as a problem in Sri Lanka. It has been reported that Aspergillus rot causes 25 - $35 \%$ loss, in Allahabad and Lucknow in India and the causative organism is Aspergillus niger van Tiegh (Srivastawa, 1968). It is now known that this

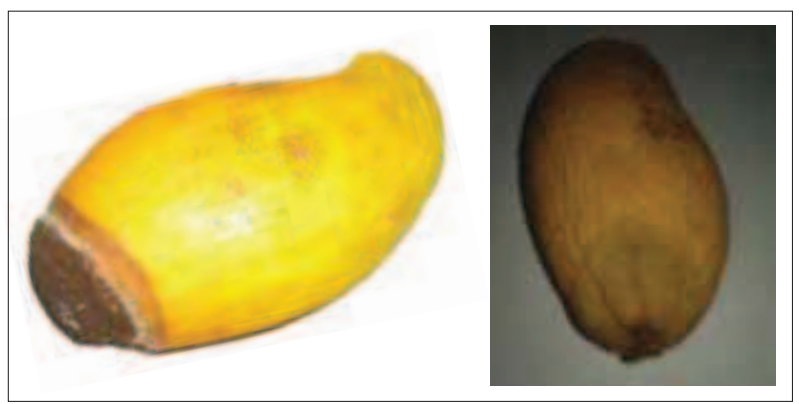

Figure 1: Aspergillus rot of Ambalavi mangoes

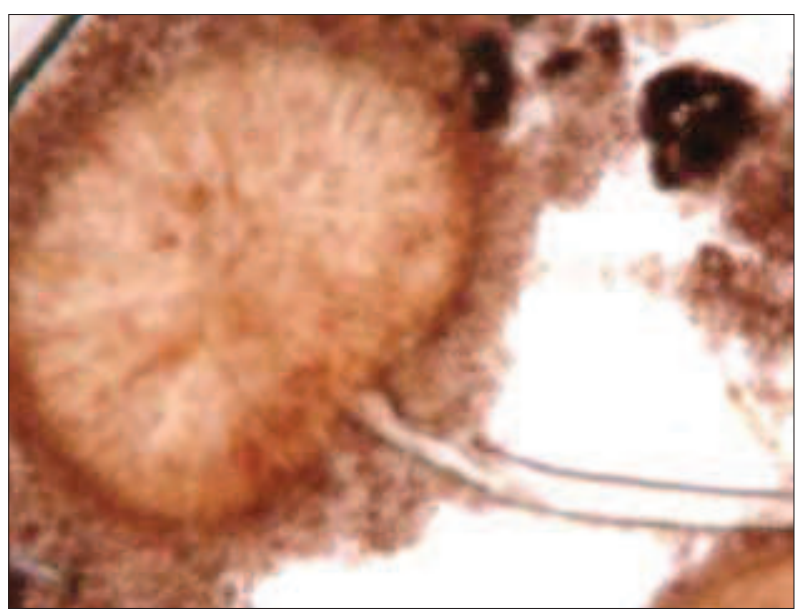

Figure 2: Aspergillus niger isolated from Karuthakolumban mangoes pathogen causes a significant economic loss to the home garden growers in Jaffna where measures are urgently needed to control the loss due to this pathogen.

This is the first report regarding the Aspergillus rot of mangoes in Sri Lanka.

\section{Acknowledgement}

The National Science Foundation of Sri Lanka (Grant No: $\mathrm{RG} / 2009 / \mathrm{AG} / 02$ ) is gratefully acknowledged for financial assistance.

\section{REFERENCES}

1. Bennett J.W. (2010). An overview of the genus Aspergillus. Aspergillus Molecular Biology and Genomics (eds. Masayuki Machida \& Katsuya Gomi), pp. 1 - 19. Caister Academic Press, Norwich, UK.

2. Gautam K.A., Sharma S., Avasti S. \& Bhadauria R. (2011). Diversity, pathogenicity and toxicology of $A$. niger: an important spoilage fungi. Research Journal of Microbiology 6(3): $270-280$.

3. Johnson G., Muirhead I., Mayers P. \& Cooke T. (1997). Diseases. Postharvest Pests and Disorders of Mangoes. Queensland Department of Primary Industries Information Series, pp. 1 - 9. Queensland Department of Primary Industries, Queensland, Australia.

4. Perrone G.A., Susca G., Ethrlich K.C. \& Vargas J. (2007). Biodiversity of Aspergillus species in some important agricultural products. Studies in Mycology 59: 53 - 66 .

5. Pitt J.T. \& Hocking A.D. (2009). Fungi and Food Spoilage. $3^{\text {rd }}$ edition, pp. 275 - 337. Springer Science, New York, USA.

6. Prakash O. \& Raoof M.A. (1989). Control of mango fruit decay with postharvest applications of various chemicals against black rot, stem-end rot and anthracnose diseases. International Journal of Tropical Plant Diseases 6: $99-106$.

7. Srivastawa O.P. (1968). Soft rot on "desi" mango fruit and the pathogenicity of the isolated microorganisms. Journal of the Indian Botanical Society 47: 328 - 329.

8. Watanabe T. (2002). Pictorial Atlas of Soil and Seed Fungi, Morphologies of Cultured Fungi and Key to Species, $2^{\text {nd }}$ edition, p. 486. CRC Press, UK. 